\title{
COMPUTATIONAL INVESTIGATION OF CRACK INDUCING FORCES ON BEARING SURFACES REGARDING THE TRIBOFILM STRUCTURE
}

\author{
FLORIAN PAPE, MARTIN PETZOLD \& GERHARD POLL \\ Institute for Machine Design and Tribology, Leibniz University Hannover, Germany.
}

\begin{abstract}
To reduce wear in tribosystems, the formation of a protective tribofilm is beneficial. By applying additives to the lubricating oil or grease, an anti-wear boundary layer can be achieved. For simulating the induced stresses on the bearings surface, the formed tribofilm should be regarded. In this study, cylindrical roller thrust bearings were investigated regarding a tribofilm formed by oil containing zinc dialkyldithiophosphate (ZDDP) additives. Due to the test conditions, a smooth film with low roughness forms on the surface. The film consists of glassy Fe/Zn polyphosphates with a height of up to $150 \mathrm{~nm}$ and a width of approximately $1 \mu \mathrm{m}$. Based on the roughness, the surface was modelled with regularly distributed dimples to be used for a finite element model for the contact between a roller and a bearing washer regarding contact stress and tangential forces due to slip. The dimples in the contact between roller and washer lead to an inhomogeneous pressure distribution near the surface. During the contact, the surface pads of the roller partly slide over the surface pads of the washer in dependence of the contact position. Of particular interest is the deformation in running direction. If the asperities of the roller press against the washers asperities, a significant deformation at the dimples and in the volume underneath occurs. As expected, the strains occur in the regions with high deformation gradients. During rolling, the deformations lead to areas that are stretched and compressed. The maximum strains are located between the dimples and shift in rolling direction from pad to pad. It has to be assumed, that the formation of cracks starts between the dimples at the surface and develop along the stretched areas whereas the cracking in the compressed areas is suppressed or at least impeded. The simulative results were compared to literature proving that the values determined by simulation are in well agreement.

Keywords: Bearing, Crack Formation White Etching Cracks, Tribofilm, Friction, Zinc dialkyldithiophosphate.
\end{abstract}

\section{INTRODUCTION}

In order to minimize wear in machine elements under relative motion lubrication is mandatory. To reduce wear special additives are added to the lubricant. For application in gears, the additive zinc dialkyldithiophosphate (ZDDP) is frequently used. Under the influence of the additive, a tribological boundary layer is formed on bearing surfaces under operational conditions. The layer formation is favoured by high shear stresses under high contact pressures and therefore initially forms at local roughness peaks. The layer thickness increases and rough phosphate-containing pads are formed. As the size of the pads increases, the pressure acting on them decreases, which is why the process ends at a maximum layer thickness of approx. $150 \mathrm{~nm}$. The tribofilm formation is additional influenced by the temperature [1]. Due to thermal and oxidative effects, the ZDDP decomposes in the tribological contact, initiated by migration of alkyl groups from oxygen to sulphur atoms [2]. Fujita and Spikes proved that ZDDP based films can be generated even at room temperature on surfaces under relative motion [3]. In liquids with higher frictional properties, as a result of higher tangential forces acting on the friction bodies, the formation of a boundary layer is much more pronounced. The pads consist of zinc polyphosphate at the surface. The transition to the base material consists of a sulphur-containing layer [4]. 
The components zinc, phosphate and sulphur can be proven up to a layer thickness of $70-140 \mathrm{~nm}$. A structural change is formed up to $250-450 \mathrm{~nm}$ in the base material [5], [6]. The surface layer protects the friction partners and reduces wear, since the newly formed surface layers prevent direct contact between the base materials of the individual friction partners. The presence of ZDDP in combination with Ca cations and sulfur anions in the tribofilm was confirmed in current investigations of early bearing failure due to White Etching Cracks (WECs) [7]-[9].

Roller bearings are typically made of 100Cr6 bearing steel (German standard corresponding to AISI 52100). In roller bearings, the contact between raceway and rolling elements is exposed to high cyclic loads. Alternating stresses are induced in varying depths beneath the surface of the contacting partners. Depending on the geometry of the contacting bodies, this leads to a point or line contact in the contact zone. Due to local elastic deformation, an elliptical contact surface is created at the point contact and a rectangular contact surface at the line contact. The surface pressure can be calculated using Hertz's contact theory. As with all models, there are also some simplifications for the contact models according to Hertz. It is assumed that the contact partners only touch each other in a very small area, that the materials of the contact partners are isotropic and homogeneous, that the contact surface is ideally smooth and that there are no residual stresses inside the material. In addition, the model is only valid for purely elastic deformations [10], [11].

The investigated roller thrust bearings of type 81212 have cylindrical rolling elements (rollers), which are held by a polyamide cage. For this kind of bearings, it has to be regarded, that on the middle of the raceway no slip occurs between roller and bearing washer, while asides the raceway higher slip is achieved. Figure 1 shows the bearing components.

In order to be able to recreate the contact area in as much detail as possible, the geometry must be reduced to a very small section in the micrometre range (Fig. 2). This makes it possible to handle the calculation time in the subsequent simulation. The first simplification consists in the fact that not the entire cylindrical roll is mapped, but only disc pieces at defined positions of the contact zone. In order of a higher simplification of the model, only the centre of the contacting zone of the respective disc piece is considered.

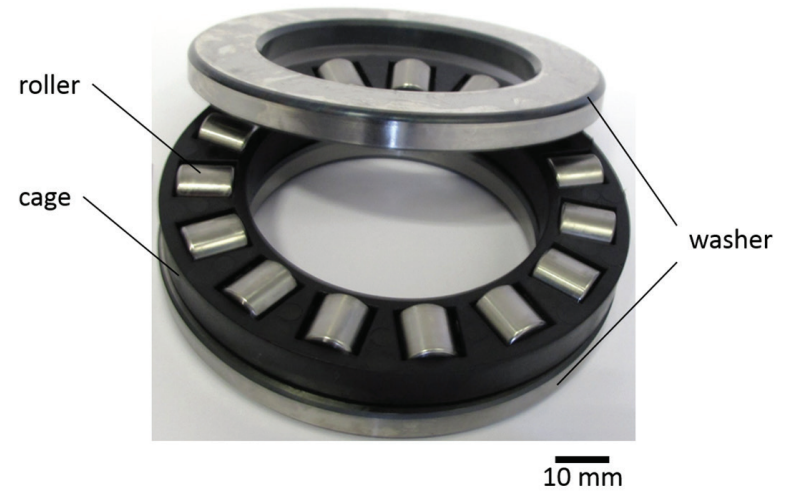

Figure 1: Components of the axial roller thrust bearing type 81212. 


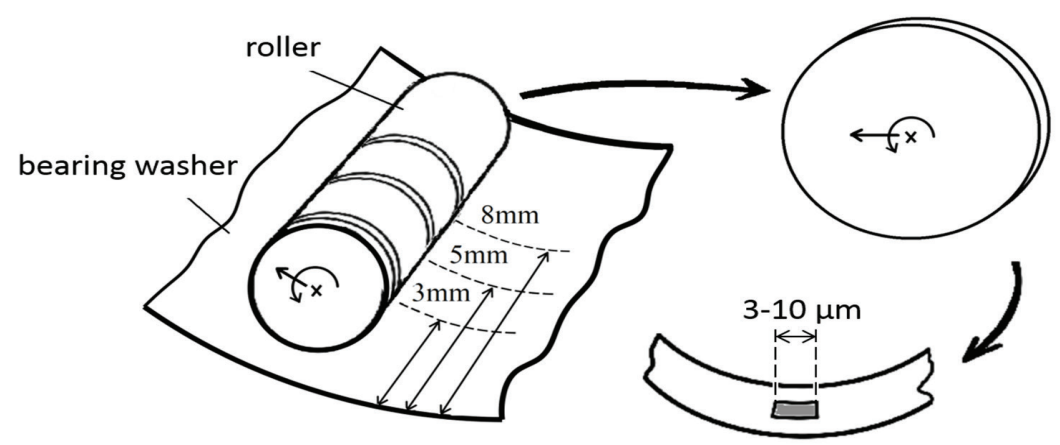

Figure 2: Contact between roller and bearing washer with modelled contact area.

\section{EXPERIMENTAL SETUP}

To set up the surface structure of a bearing regarding the tribofilm axial bearing washers were tested in a FE-8 test rig. The test was performed under lubrication with a less additivated oil containing ZDDP additives. The oil was supplied at a constant flow rate of $0.1 \mathrm{l} / \mathrm{min}$. Figure 3 depicts the setup of the test rig. The test is specified in the standard DIN 51819 for the mechanical-dynamic measurement of rolling contact bearing lubricants. The test was carried out at a temperature of $100^{\circ} \mathrm{C}$. In a first step, the bearings were tested for $24 \mathrm{~h}$ at $250 \mathrm{rpm}$, followed by additional $26 \mathrm{~h}$ at $750 \mathrm{rpm}$ (until early failure of one bearing due to White Etching Cracks [12]). To stabilize the bearing temperature, a fan cooled the test head. A preload of $60 \mathrm{kN}$ was applied to the bearing washers via disc springs resulting in a Hertzian pressure of $1.9 \mathrm{GPa}$. The tribofilm structure was investigated by scanning probe microscopy (SPM) of the surface. The tribofilm structure of a tested axial bearing washer on a zone under higher induced slip is shown in Fig. 4. The tribofilm was additional investigated in terms of time-of-flight secondary ion mass spectrometry (ToF-SIMS) proofing the composition of phosphate-glass, Ca cations and sulfur anions [12].

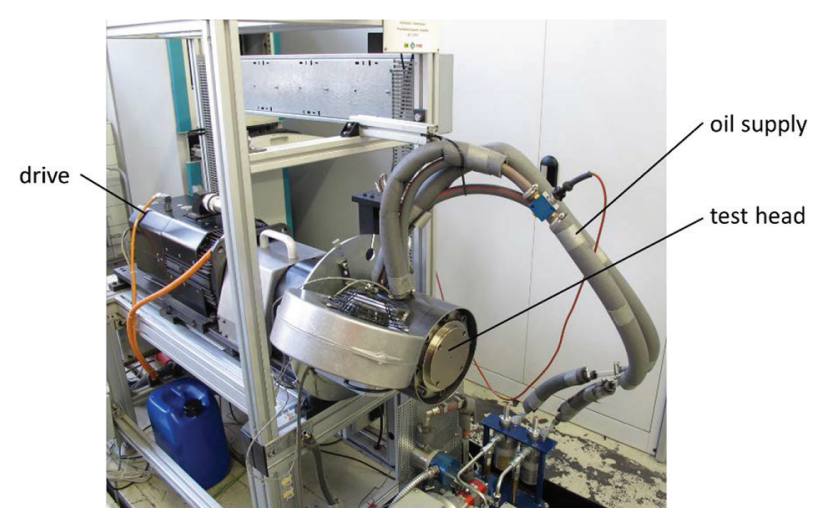

Figure 3: Test rig 51819 for the mechanical-dynamic measurement of rolling contact bearing lubricants. 


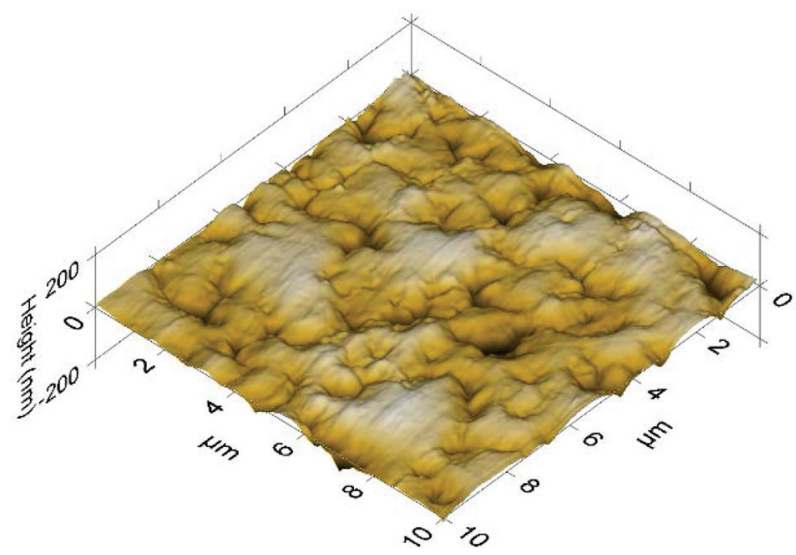

Figure 4: Surface structure (scanning probe microscopy) on bearing washer.

\section{MODELLING THE TRIBOLOGICAL CONTACT}

To conclude on the induced stresses and reactions in the tribological contact zone the tribofilm roughness has to be regarded in simulation models. When modelling the surface structure, the first step is to identify those parameters to be chosen to simulate the real structure as accurate as possible. The structure should be transformed into a uniform structure. This is done for two reasons. On the one hand, the modelling effort is reduced in this way, since with an irregular structure a statistical evaluation and generation of the surface structure would have to take place. On the other hand, the characteristic structure at the corresponding position is to be emphasized and examined in this way. The respective surface is modelled by a sequence of (half) spheres (Fig. 5).

To identify the parameters, the coordinates achieved by scanning probe microscopy from [13] were evaluated in Matlab. Since a circle can be described with three coordinates, three

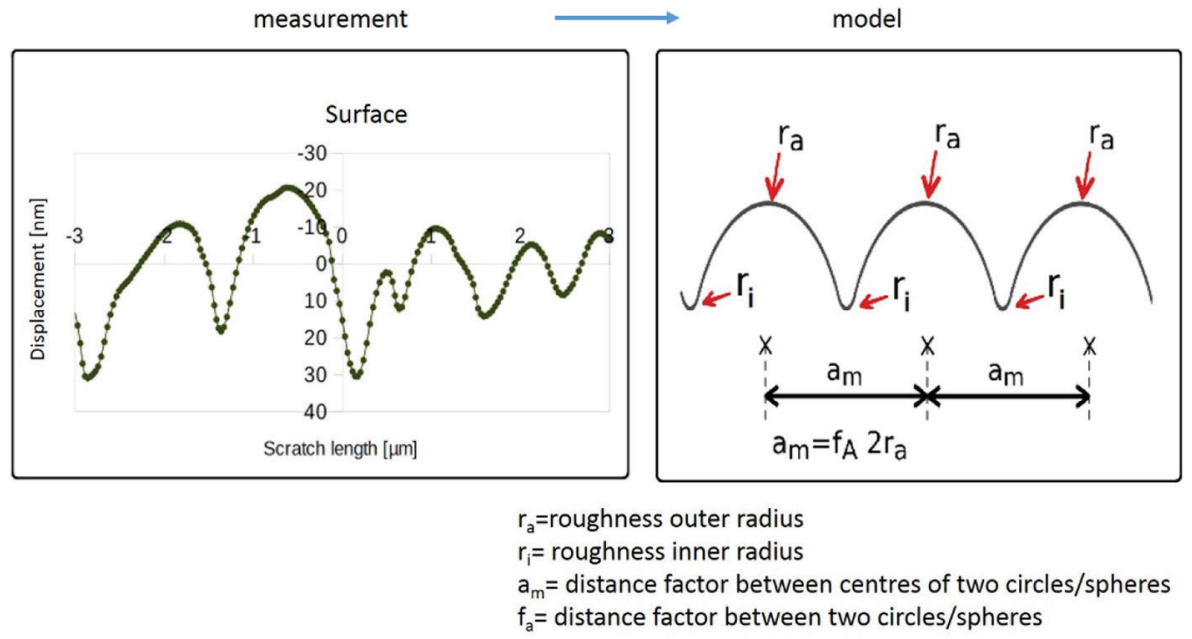

Figure 5: Modelling of surface fine structure. 
coordinates were selected for the calculation of the outer $\left(\mathrm{r}_{\mathrm{a}}\right)$ and inner $\left(\mathrm{r}_{\mathrm{i}}\right)$ radii of the spheres. The coordinates for the 'outer radius' were also used to calculate the distance factor $\mathrm{a}_{\mathrm{m}}$ between the centres of two spheres. For this purpose, the outer points of a sphere were selected in such a way that they adjoin the adjacent spheres on the left and right as shown in Figure 5.

A FE-model was set up in the finite element software ANSYS. A first loading step was used for the contact and pressure between roller and washer, in a second load step the roller was put into a state of motion which corresponds to the real rolling process at a speed of $\mathrm{n}=750 \mathrm{rpm}$. The rolling process, in which a positive or negative slip can also occur depending on the position, is realized by a combination of translation and rotation. In the simulation model, only a sector of central contact area was chosen. Thus, only a very small distance of a few micrometres was considered, as shown in Fig. 6.

Therefore, the simulation model assumes a purely translational movement. Even if the simulation model does not include rotation, this must still be taken into account, since rotation has an effect on the tangential velocity in the contact area. For friction between the roller and bearing washer values detected by micro-pin-on-disc tests achieved in previous work were chosen [12]. In our case, the coefficient of friction was set to 0.095 for the contact. The washer was fixed in all directions, both translatory and rotatory. The side surfaces of the roller and washer can only be moved in translation perpendicular to the contact surface. This is to enable pressing and contact between the friction partners. The only exception is the translation of the roller piece in the longitudinal axis, as this is already determined by the second load step. The longitudinal and vertical axes of the roller piece are fixed rotatable to prevent rolling and yawing during the second load step. The contact between roller and washer was made with the Pure-Penalty method. This is intended to simplify the convergence process. The contact is asymmetrical on all models. Since the contact surface of the washer is the projecting surface, this was selected as the master and the contact surface of the roller piece as the slave. The cylindrical roller and the bearing washer were defined as 100Cr6 (AISI 52100) bearing steel. A purely elastic material behaviour was assumed. All geometries were meshed with hexahedral elements.

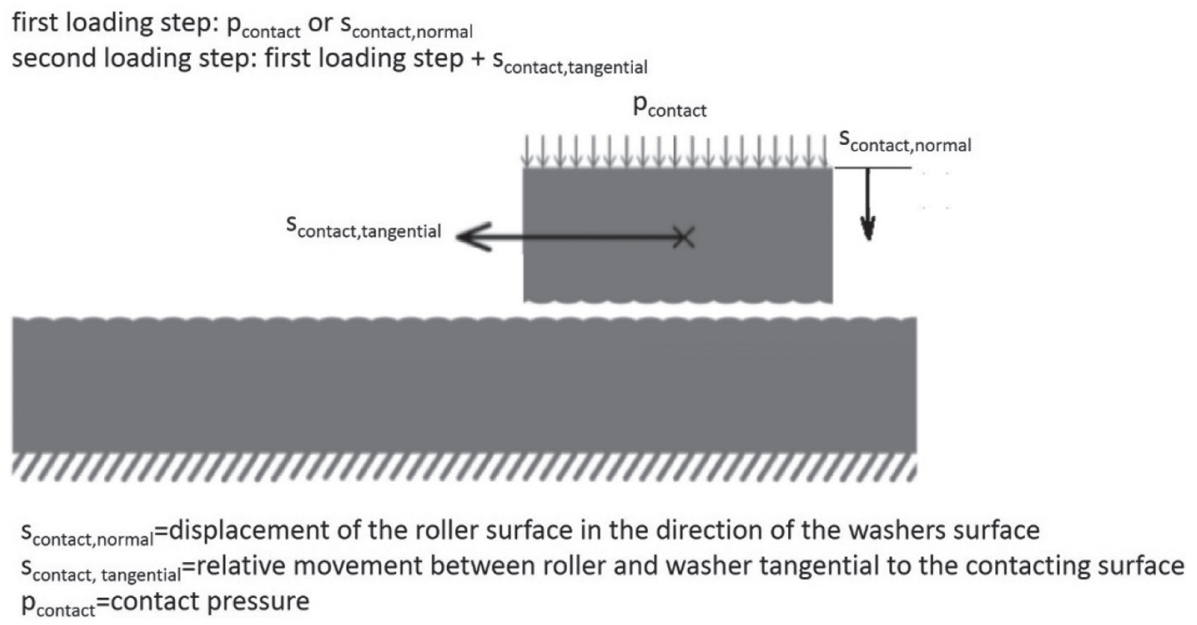

Figure 6: Simulation model of the contact between roller and bearing washer. 


\section{CALCULATION RESULTS}

The inhomogeneous surface structure in the contact of roller and washer results in an inhomogeneous pressure distribution nearby the surface. In dependence of the contact position, the surface pads of the roller partly slide over the surface pads of the washer during the contact. Due to the movement of the roller along the uneven surface, the subsurface areas are alternatingly stretched and compressed. Between the dimples, maximum positive strains are located. These strains are shifted in rolling direction from pad to pad. It can be assumed, that crack formation in the boundary layer starts at the surface and expands along the stretched areas. In contrast cracking in the compressed areas would be suppressed or at least impeded. The elastic deformation for a zone of positive slip on a bearing washer is shown in Fig. 7. The surface is pulled apart at the depressions (blue surface). If a crack develops from the depression, it can be assumed that it would preferably extend to zones with high local strain (tensile) at an angle of $30^{\circ}$ resp. $20^{\circ}$ to the running direction. The sliding of a surface pad over the surface pad of the counter body leads to the formation of an area inside the material next to roughness depressions, which is tensile stressed (in running direction). During the contact, these tensile-stressed zones move further and further in the direction of travel to the next depression. The surface-induced stresses result in particularly high strains of up to $0.7 \%$. The areas with increased compression (in the z-axis) also move in the running direction, but start at a roughness peak and have their maximum value below the depressions. A qualitative course is shown in Fig. 8.

In case that the crack propagation does not occur exactly in the running direction, but diagonally, then the angles are reduced to approx. $20^{\circ}$ and $18^{\circ}$ (Fig. 9). It can therefore be assumed that the cracks tend to propagate along the surface if they do not propagate exactly in the running direction but diagonally at an angle of approx. $45^{\circ}$.

Experimentally found values in literature agree well with those determined by simulation [14]. Also Ryerz et al. observed cracks with an angle of inclination of $20-30^{\circ}$ to the surface and propagation against the direction of friction force by applying a triple contact test rig under mixed lubrication conditions [15].

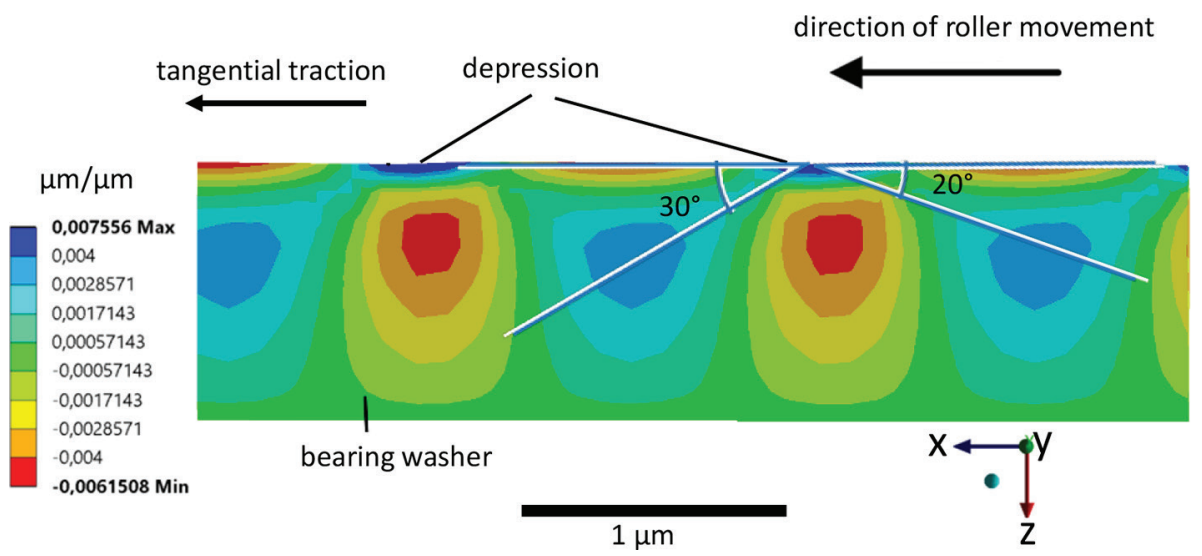

Figure 7: Transient simulation for the positive slip area of a bearing washer with an uneven surface (represented by a sinusoidal wave), showing the local strains parallel to the surface (based on the local elongation in x-direction) induced by frictional tangential stresses at the surface. 


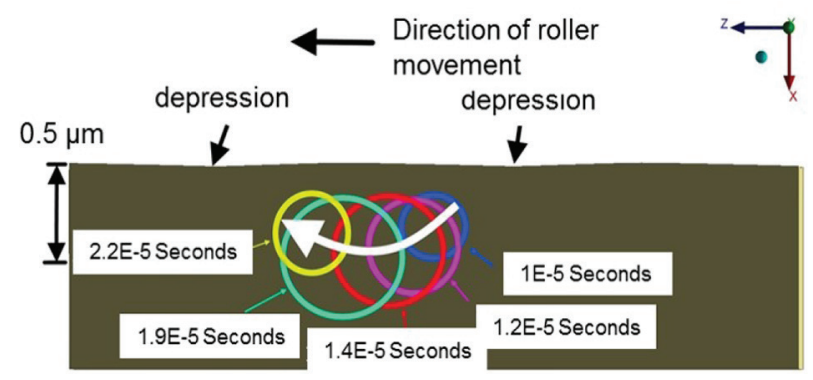

Figure 8: Transient simulation for the positive slip area of a bearing washer with an uneven surface (represented by a sinusoidal wave), showing travel of a compressed zone under a roughness peak on the surface.

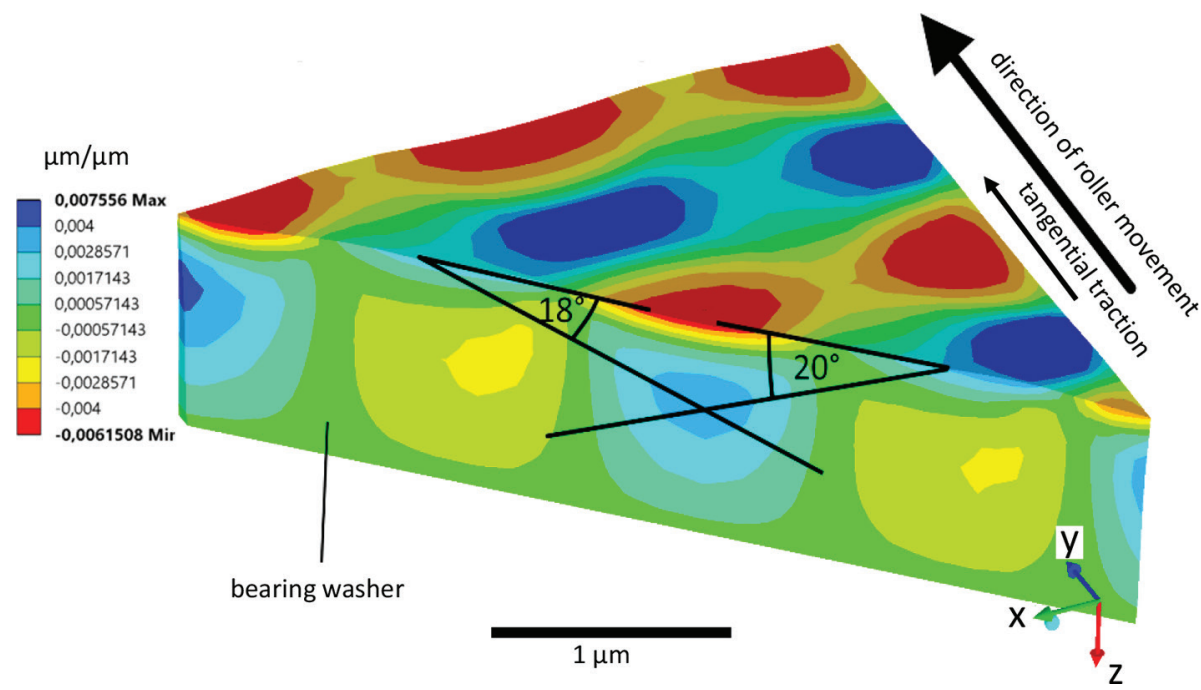

Figure 9: Transient simulation for the positive slip area of a bearing washer with an uneven surface (represented by a sinusoidal wave), showing the local strains parallel to the surface and crack propagation diagonally in the running direction.

It should generally be noted that the real surface structure is not uniform in reality and the excitations are subject to certain fluctuations. Even if relatively low stresses and strains are applied inside the material, this can still lead to a high load on the microstructure during continuous operation due to the very high alternating loads. While the roller rolls over the washer, the load is applied at a very high frequency due to the fine surface structure.

If it is assumed that a new load is caused by one surface pad sliding over another, the excitation frequency at a position under high slip is approx. $39 \mathrm{kHz}$. It should be noted that the real surface structure is uneven compared to the model and therefore no ideal harmonic excitation takes place. After the alternating load due to the rollover, the roller leaves the contact area under consideration until the next roller stresses it and causes a new alternating load. This again occurs with 15 (evenly) distributed rolling elements and a speed of $750 \mathrm{rpm}$ at a frequency of $187.5 \mathrm{~Hz}$ or a time interval of $0.0053 \mathrm{~s}$ (Fig.10). 


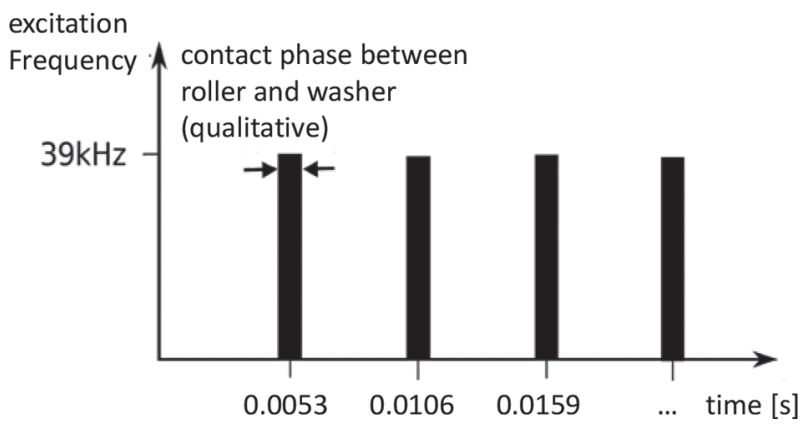

Figure 10: Frequency of loads on surface dimples due to cyclic contact.

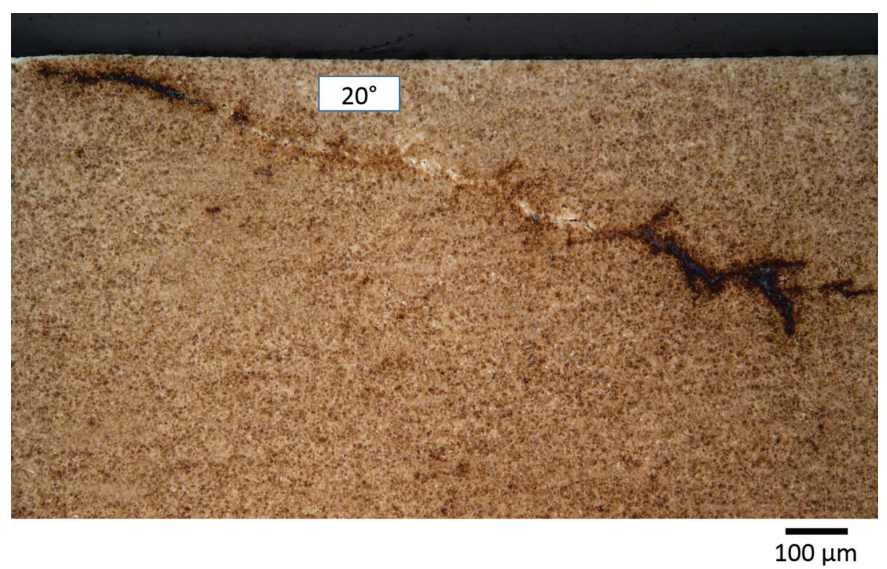

Figure 11: White Etching Crack on axial bearing washer, cross section of bearing washer after test in FE8 test rig. Angle of crack inclination approx. $20^{\circ}$ to the surface.

Due to the high cycle of loads, the tribofilm is stressed and hydrogen atoms can easier diffuse into the subsurface along the pulled apart zones. As hydrogen results in brittle material behaviour and cause subsurface crack propagation, it is suspected as a driver of early bearing failure and White Etching Cracks (WECs) [16], [17]. These cracks feature a white etching area aside the crack itself and can be found on early failed bearings [18]. Figure 11 shows a cross section of a WEC featuring an angle of inclination of approx. $20^{\circ}$.

\section{CONCLUSION}

The aim of this work was to numerically calculate the rolling process of an axial cylindrical roller bearing under slip conditions and under consideration of a tribological boundary layer in the contact area in an FE simulation. The tribological boundary layers formed on the contact surface due to the additive ZDDP were regarded. These boundary layers are very flat and, depending on their position on the bearing raceway, have a roughness depth between 5 and $80 \mathrm{~nm}$. For the determination of the parameters, which are necessary for the modelling of the surface structure, measured profiles from a scanning-probe method were evaluated in Matlab. The calculation in the FE method was transient, so that, in contrast to the static calculation, 
dynamic influences such as inertia effects could also be taken into account. It could be shown that the inhomogeneous structure in the contact between roller and washer causes an inhomogeneous pressure distribution directly under the surface. The subsurface pressure distribution allows concluding on the crack propagation, which is in accordance with literature. It was proven that cracks develop preferable in an angle of $30^{\circ}$ resp. $20^{\circ}$ to the running direction due to the tensile subsurface strains.

\section{ACKNOWLEDGMENT}

This work was sponsored in part by the DFG (German Research Centre) within the research program 'Influence of stress states in rolling bearings on White Etching Cracks' (DFG-PO675/9-1). The results presented here were (partially) carried out on the cluster system at the Leibniz University of Hannover, Germany.

\section{REFERENCES}

[1] Pape, F., Mallach, D., Lipinsky, D., Arlinghaus, H.F. \& Poll, G., Investigations of boundary layers generated in a micro pin-on-disk tester, Presentation, 45th Leeds-Lyon Symposium in Tribology 2018, Smart Tribology Systems, Leeds, UK, 2019.

[2] Neville A. \& Morina, A., Wear and Chemistry of Lubricants, Wear: Materials, Mechanisms and Practice, eds. G.W. Stachowiak, Wiley, Chichester, England Hoboken, NJ, 2005.

[3] Fujita, H. and Spikes, H.A., The formation of zinc dithiophosphate antiwear films, Proceedings of the Institution of Mechanical Engineers. Part J: Journal of Engineering Tribology, 218(4), pp. 265-277, 2004.

[4] Bares, J.A., Carpick, R.W., Gosvami, N.N., Konicek, A.R., Mangolini, F. \& Yablon, D.G., Mechanisms of antiwear tribofilm growth revealed in situ by single-asperity sliding contacts. Science, 348(6230), pp. 102-106, 2015.

[5] Gachot, C., Hsu, C., Suárez, S., Grützmacher, P., Rosenkranz, A., Stratmann, A. \& Jacobs, G., Microstructural and chemical characterization of the tribolayer formation in highly loaded cylindrical roller thrust bearings. Lubricants, 4(2), 2016.

[6] Zhang, J. \& Spikes, H., On the mechanism of ZDDP antiwear film formation. Tribology Letters, 63(2), p. 24, 2016. https://doi.org/10.1007/s11249-016-0706-7

[7] Lipinski, D., Muhmann, C., Arlinghaus, H.F., Möbes, G., Pape, F. \& Poll, G., Untersuchung der unter tribologischer Belastung auf Laufflächen von Axialzylinderrollenlagern gebildeten tribologischen Grenzschichten mit Hilfe von mikrotribologischen Verfahren und der Flugzeit-Sekundärionenmassenspektrometrie (ToF-SIMS), Tagungsband, Getlub Kongress, März 09.-10., Forschungsvereinigung Antriebstechnik e.V., p. 168-181, 2016.

[8] Lipinsky, D., Muhmann, C., Arlinghaus, H.F., Möbes, G., Pape, F. \& Poll, G., Grenzschichtanalysen an WEC-gefährdeten Wälzlager-Laufflächen, Bearing World, Hannover, Germany, April 12-13, 2016.

[9] Muhmann, C., Lipinsky, L., Pape, F., Möbes, G., Poll, G. \& Arlinghaus, H.F., ToF-SIMS investigation of boundary layers built up under tribological load in the runways of axial cylindrical roller bearings, SIMS Europe 2016, September 18-20, Münster, Germany, 2016.

[10] Wittel, H., Muhs, D., Jannasch, D. \& Voßiek, J. (Hrsg.), Maschinenelemente, Springer Fachmedien Wiesbaden, 2011.

[11] Seherr-Thoss, H.-C. G. v., Schmelz, F. \& Aucktor, E., Gelenke und Gelenkwellen, Springer, Berlin Heidelberg, 2002. 
[12] Pape, F., Möbes, G., Lipinsky, D., Muhmann, C., Arlinghaus H.F. \& Poll, G., Investigation of the temperature influence on the formation of boundary layers on bearings. Tribologie und Schmierungstechnik, 64(5), pp. 39-46, 2017.

[13] Pape, F., Moebes, G. \& Poll, G., Space-resolved micro-tribological investigations of boundary layers on bearing surfaces. Proceedings, The 17th Nordic Symposium on Tribology, Hämeenlinna, Finland, pp. 1-15, June 14-17, 2016.

[14] Harada, H., Mikami, T., Shibata, M., Sokai, D., Yamamoto, A. \& Tsubakino, H., Microstructural changes and crack initiation with white etching area formation under rolling/sliding contact in bearing steel. ISIJ International, 45(12), pp. 1897-1902, 2005.

[15] Rycerz, P., Olver, A. \& Kadiric, A., Propagation of surface initiated rolling contact fatigue cracks in bearing steel. International Journal of Fatigue, 97, pp. 29-38, 2017.

[16] Kino, N., Otani, K., The Influence of hydrogen on rolling contact fatigue life and its improvement. JSAE Review, 24(3), pp. 289-294, 2003.

[17] Carroll, R.I. \& Beynon, J.H., Rolling contact fatigue of white etching layer. Science Direct, Wear, 262(9-10), 2007.

[18] Stadler, K. \& Stubenrauch, A., Premature bearing failures in wind gearboxes and white etching cracks. Power Transmission Engineering, 10, pp. 34-40, October, 2014. 